\title{
Empyema Caused by Pseudomonas luteola: A Case Report
}

\author{
Farid Yousefi ${ }^{1,2}$; Saeed Shoja ${ }^{2}$; Negin Honarvar ${ }^{1,2,}$ \\ ${ }_{1}^{1}$ Department of Infectious and Tropical Diseases, Razi Hospital, Faculty of Medicine, Jundishapur University of Medical Sciences, Ahvaz, IR Iran \\ ${ }^{2}$ Health Research Institute, Infectious and Tropical Disease Research Center, Jundishapur University of Medical Sciences, Ahvaz, IR Iran \\ ${ }^{*}$ Corresponding author: Negin Honarvar, Health Research Institute, Infectious and Tropical Disease Research Center, Jundishapur University of Medical Sciences, Ahvaz, IR Iran. Tel: \\ +98-9131998913, Fax: +98-6113336513, E-mail: dr.nhonarvar@yahoo.com
}

Received: February 26, 2013; Revised: May 5, 2013; Accepted: May 8, 2013

Introduction: Pseudomonas luteola is an uncommon opportunistic pathogen. It is recognized as an uncommon cause of infections in underlying medical disorders. Infections caused by this microorganism are health care associated.

Case Presentation: The current study isolated $P$. luteola from empyema in a patient with tuberculous pleurisy, whose susceptibility to trimethoprim-sulfamethoxazole differed from previous reports.

Conclusions: P. luteola is resistant to TMP-SMX, but in the present case P. luteola was susceptible to TMP-SMX

Keywords:Empyema; Pleural Effusion; Tuberculous Pleurisy; Pseudomonas

\section{Introduction}

Pseudomonas luteola is an aerobic, non-spore forming, Gram negative and rod-shaped bacterium (0.8-2.5 $\mu \mathrm{m})$. This bacterium is motile owing to the presence of one or more polar flagella. It is lactose non-fermenter and grows well on MacConkey medium (1). The optimal growth temperature is $30^{\circ} \mathrm{C}$. This species of Pseudomonas is oxidase negative and produces distinguished yellow-pigmented colonies on MacConkey agar. It does not reduce nitrate and oxidase xylose $(1,2)$. It was first described by Tatum et al. (3), and was previously known as Centers for Disease Control and Prevention (CDC) group Ve-1 and Chryseomonas luteola (1). Analysis of 16srDNA sequences of this microorganism has suggested that the genera named Chryseomonas, Flavimonas and Pseudomonas were synonymous; consequently, P. luteola was used (4). The normal habitat of $P$. luteola is unclear, although it belongs to a group of bacteria normally found in moist environments (4). They can contaminate solutions such as distilled water, disinfectants and intravenous solutions (1). There are rare reports of infections caused by P. luteola.

\section{Case Report}

A 38-years-old man with clinical sign of pulmonary tuberculosis and respiratory distress was admitted to Razi of Ahvaz, Iran in September 2012. He had symptoms such as mental retardation, non-productive cough, fever, night sweating, anorexia, pleuritic chest pain and weight loss, which lasted for a month. The patients' respiratory distress worsened during the last five days. On his physical examination, he was cachectic and there was a weak sound from the left lung. His blood test indicated the following results: No leuckocytosis, erythrocyte sedimenta- tion rate (ESR) $120 \mathrm{~mm} / \mathrm{h}$, lactate dehydrogenase $691 \mathrm{mg}$ $\mathrm{dL}$ and total protein $4.8 \mathrm{~g} / \mathrm{dL}$.

All aerobic blood cultures were negative after 72 hours. He had left lung pleural effusion on chest X-Ray (left hemithorax more than 50\%), and diagnostic pleural tap indicated as follows: white blood cell count 595/dL (PMN: 10\%, Lymph: 90\%), glucose $<10 \mathrm{mg} / \mathrm{dL}$, protein $6.1 \mathrm{gr} / \mathrm{dL}$, LDH $4804 \mathrm{mg} / \mathrm{dL}$ and Adenosine De-aminase (ADA) 107 IU, negative smear for WBC, bacteria and culture, and positive Broncho Alveolar Lavage (BAL) for acid fast bacilli. The patient with the diagnosis of pulmonary tuberculosis and tuberculous pleurisy was put under treatment with isoniazid, rifampin, ethambutol, pyrazinamide, pyridoxine; and chest tube was inserted. Twelve days later, purulent discharge was observed in his chest tube; therefore, re-tapping was done. This time, his test results were as follows:

Appearance was turbid and WBC was 76000/dL (PMN: 99\%, Lymph: 1\%) many WBC and many Gram negative bacilli were observed on smear and P. luteola isolated and diagnosed after 48 hours. P. luteola was sensitive to trimethoprim-sulfamethoxazole (TMP-SMX), intermediate to gentamycin and resistant to cefepime, ciprofloxacin, norfloxacin, ampicillin, and nalidixicacid. Accordingly, the patient with the diagnosis of empyema was treated with TPM-SMX ( $5 \mathrm{mg} / \mathrm{kg}$ from TMP), as a result of which, his chest tube discharge decreased to $50 \mathrm{~mL} / 24$ hours. Then he was referred for pleural decortication.

\section{Conclusions}

Based on background, physical examination, and pleural tap, the patient had tuberculous pleurisy and empyema. Isolation of P. luteola from empyema demonstrated

Copyright (c) 2014, Ahvaz Jundishapur University of Medical Sciences; Published by Kowsar Corp. This is an open-access article distributed under the terms of the Creative Commons Attribution License, which permits unrestricted use, distribution, and reproduction in any medium, provided the original work is properly cited. 
the etiological role of these bacteria. No case of empyema caused by P. luteola had been reported before; nevertheless previous studies showed that P. luteola may cause bloodstream infections associated with intravenous indwelling catheters, prosthetic valve endocarditis, pancreatitis, foreign bodies and cutaneous abscesses. Rarely, non-bacteremic cases have been reported as post neurosurgical infections, peritonitis complicating appendicitis or peritoneal dialysis catheters, fatal meningitis, femur abscess, endophthalmitis, facial cellulitis, subphrenic abscess, leg ulcer in a patient with sickle disease, and hand infection (2-16).

The use of steroids and other immunodepressive therapy, the presence of a foreign body, and postsurgical instability have been suggested to predispose to infection with P. luteola; therefore nosocomial infections are more frequent than community acquired ones (18). Clinical isolates of $P$. luteola are often resistant to first- and secondgeneration cephalosporins and tetracyclines, ampicillin, and TMP-SMX, but are susceptible to third-generation cephalosporins, mezlocillin, imipenem, aminoglycosides, and quinolones $(1,5)$. Contrary to the previous case reports in which $P$. luteola was resistant to TMP-SMX, in the present case P. luteola was susceptible to TMP-SMX and the patient showed clinical response to the treatment with TMP-SMX. Finally, when decortication was performed for the patient, treatment continued with TMPSMX and anti-tuberculosis drugs, and the patient was discharged with relative improvement after two weeks.

\section{Acknowledgements}

Authors would like to thank the staff of Microbiology Department of Jundishapur University of Ahvaz for their help.

\section{References}

1. James PS, Eileen M. B.. Other gram negative and gram variable bacilli.Principeles and practice of infectious disease. 7 th ed: Churchill living; 2010.

2. Chihab W, Alaoui AS, Amar M. Chryseomonas luteola identified as the source of serious infections in a Moroccan University Hospital. J Clin Microbiol. 2004;42(4):1837-9.

3. Tatum HW, Ewing WH, Weaver RE. Miscellaneous Gram-negative bacteria. In: Lennette EH, Spaulding EH, Truant JP editors. Manual of Clinical Microbiology. 2th ed. Washington DC: American Society for Microbiology; 1974. pp. 270-94.

4. Casalta JP, Fournier PE, Habib G, Riberi A, Raoult D. Prosthetic valve endocarditis caused by Pseudomonas luteola. BMC Infect Dis. 2005;5:82.

5. Rahav G, Simhon A, Mattan Y, Moses AE, Sacks T. Infections with Chryseomonas luteola (CDC group Ve-1) and flavimonas oryzihabitans (CDC group Ve-2). Medicine (Baltimore). 1995;74(2):83-8.

6. O'Leary T, Fong IW. Prosthetic valve endocarditis caused by group Ve-1 bacteria (Chromobacterium typhiflavum). J Clin Microbiol.1984;20(5):995.

7. Connor BJ, Kopecky RT, Frymoyer PA, Forbes BA. Recurrent Pseudomonas luteola (CDC group Ve-1) peritonitis in a patient undergoing continuous ambulatory peritoneal dialysis. J Clin Microbiol.1987;25(6):1113-4.

8. Freney J, Hansen W, Etienne J, Vandenesch F, Fleurette J. Postoperative infant septicemia caused by Pseudomonas luteola (CDC group Ve-1) and Pseudomonas oryzihabitans (CDC group Ve-2).J Clin Microbiol.1988;26(6):1241-3.

9. Hawkins RE, Moriarty RA, Lewis DE, Oldfield EC. Serious infections involving the CDC group Ve bacteria Chryseomonas luteola and Flavimonas oryzihabitans. Rev Infect Dis. 1991;13(2):25760.

10. Kostman JR, Solomon F, Fekete T. Infections with Chryseomonas luteola (CDC group Ve-1) and Flavimonas oryzihabitans (CDC group Ve-2) in neurosurgical patients. Rev Infect Dis. 1991;13(2):233-6.

11. Engel JM, Alexander FS, Pachucki CT. Bacteremia caused by CDC group Ve-1 in previously healthy patient with granulomatous hepatitis. J Clin Microbiol. 1987;25(10):2023-4.

12. Rastogi S, Sperber SJ. Facial cellulitis and Pseudomonas luteola bacteremia in an otherwise healthy patient. Diagn Microbiol Infect Dis. 1998;32(4):303-5.

13. Ghosh SK. A rare infection caused by Chryseomonas luteola.J Infect. 2000;41(1):109-10.

14. Chang JS, Chou C, Lin YC, Lin PJ, Ho JY, Hu TL. Kinetic characteristics of bacterial azo-dye decolorization by Pseudomonas luteola. Water Res. 2001;35(12):2841-50.

15. Tsakris A, Hassapopoulou H, Skoura L, Pournaras S, Douboyas J Leg ulcer due to Pseudomanas luteola in a patient with sickle cell disease. Diagn Microbiol Infect Dis. 2002;42(2):141-3.

16. Jayagopal S, Berry MG, Ross G, Howcroft AJ. Hand infection caused by Chryseomonas luteola. Br J Plast Surg. 2004;57(7):694-5. 